\title{
Effects of nearby buildings on lightning induced voltages on overhead power distribution lines
}

\author{
Alberto Borghetti ${ }^{\mathrm{a}, *}$, Fabio Napolitano $^{\mathrm{a}}$, Carlo Alberto Nucci ${ }^{\mathrm{a}}$, Mario Paolone ${ }^{\mathrm{b}}$ \\ a University of Bologna, Italy \\ ${ }^{\mathrm{b}}$ Swiss Federal Institute of Technology (EPFL), Lausanne, Switzerland
}

\section{A R T I C L E I N F O}

\section{Article history:}

Available online 8 June 2012

\section{Keywords:}

Finite element method

Lightning-induced voltages

Overhead lines

\begin{abstract}
A B S T R A C T
For the case of urban overhead lines, the presence of nearby buildings is expected to affect the overvoltages induced by nearby cloud-to-ground lightning return strokes. So far, this effect has been seldom taken into account in the literature on the subject. The paper presents a 3D FEM model that calculates the lightning electromagnetic pulse (LEMP) taking into account the presence of a building placed in proximity of the LEMP-coupled overhead line. As a first approximation, all the metallic elements are assumed as perfect conductors, as well as the ground plane. The calculated fields are then introduced in the Agrawal et al coupling model for the calculation of the induced voltages. The results of a sensitivity analysis carried by varying the model and dimensions of the building, its distance to the line and the position of the lightning stroke location are presented and discussed.
\end{abstract}

(C) 2012 Elsevier B.V. All rights reserved.

\section{Introduction}

In many countries, urban distribution networks are composed by overhead lines placed near taller buildings. Metallic beams and other conducting parts in the building may substantially affect the electromagnetic field produced by nearby return stroke lightning currents [1].

Several studies have been carried out in order to analyze the lightning induced electromagnetic fields inside struck buildings (e.g. [2-5]). Other studies, based on experimental tests and computer models, have been carried out in order to investigate the effects of nearby buildings on the electric and magnetic fields radiated by lightning (e.g. [6-8]). The results show that there is an enhancement of the lightning electromagnetic pulse (LEMP) at the building roof, particularly for the electric field, whereas, at the ground level, this quantity experiences a significant reduction.

The reduction of lightning-induced voltages on power distribution lines due to the shielding effects of nearby buildings is analyzed in [9] by means of a reduced scale model. The network model, placed above an aluminum plane simulating a perfectly conductive ground, is coupled with the electromagnetic pulse produced by a simulated lightning channel composed by a copper conductor wounded on an insulating rod. The current injected into the rod is produced by a specifically developed current-pulse generation

\footnotetext{
* Corresponding author. Tel.: +39 051209 3475; fax: +39 0512093470.

E-mail address: alberto.borghetti@unibo.it (A. Borghetti).
}

system. The presence of nearby buildings is simulated by means of aluminum structures connected to the ground.

In [10] the measured voltages on the scale model without buildings have been successfully reproduced by using the LIOV-EMTP code [11-13] for the calculation of the voltages induced by lightning return strokes on multiconductor lossy overhead lines. The LEMP-to-line coupling model adopted by the LIOV code is the one proposed by Agrawal et al. [14]. For the case of a single conductor overhead ideal line, the model is represented by the following equations:

$$
\begin{aligned}
& \frac{\partial v^{s}(x, t)}{\partial x}+L^{\prime} \frac{\partial i(x, t)}{\partial t}=E_{x}^{e}(x, h, t) \\
& \frac{\partial i(x, t)}{\partial x}+C^{\prime} \frac{\partial v^{s}(x, t)}{\partial t}=0 \\
& v(x, t)=v^{s}(x, t)-\int_{0}^{h} E_{z}^{e}(x, z, t) d z
\end{aligned}
$$

where $v(x, t)$ is the total voltage at point $x$ of the conductor and at time $t ; v_{\mathrm{s}}$ represents the so-called scattered voltage and $i$ the current; $L^{\prime}$ and $C^{\prime}$ are per unit length parameters of the line of height $h ; E_{x}^{e}$ and $E_{z}^{e}$ are two components of the lightning-originated exciting electric field, namely the component of the horizontal electric field along the line direction and the vertical one, respectively. The coupling model is numerically solved by applying a second order Finite-Difference Time-Domain (FDTD) scheme [15]. The LIOV code calculates $E_{x}^{e}$ and $E_{z}^{e}$ by means of the dipole technique and of the Master-Uman equations [16]. The Cooray-Rubinstein 


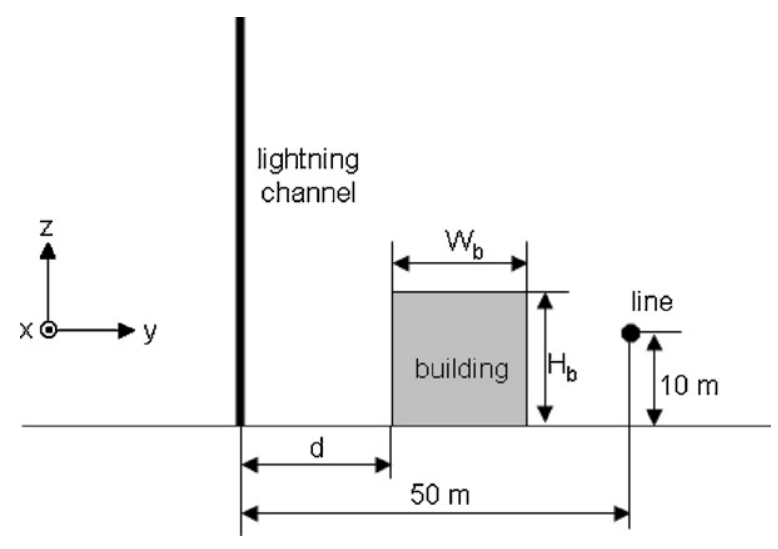

Fig. 1. Lateral cross-section of the model.

formula [17-19] is adopted to take into account the effect of the finite conductivity of the ground on the propagating field.

In this paper, the calculation of LEMP is carried out by a three dimensional (3D) finite element (FEM) model developed in order to take into account the presence of nearby buildings. The calculated $E_{x}^{e}$ and $E_{z}^{e}$ are then provided as inputs to the LIOV code in order to analyze the effect of the buildings on the induced voltages along an overhead line. As a first approximation, all the metallic structures are assumed as perfect conductors, as well as the ground plane.

The remaining sections deal with the following contents. Section 2 presents the implemented 3D FEM model. Section 3 illustrates
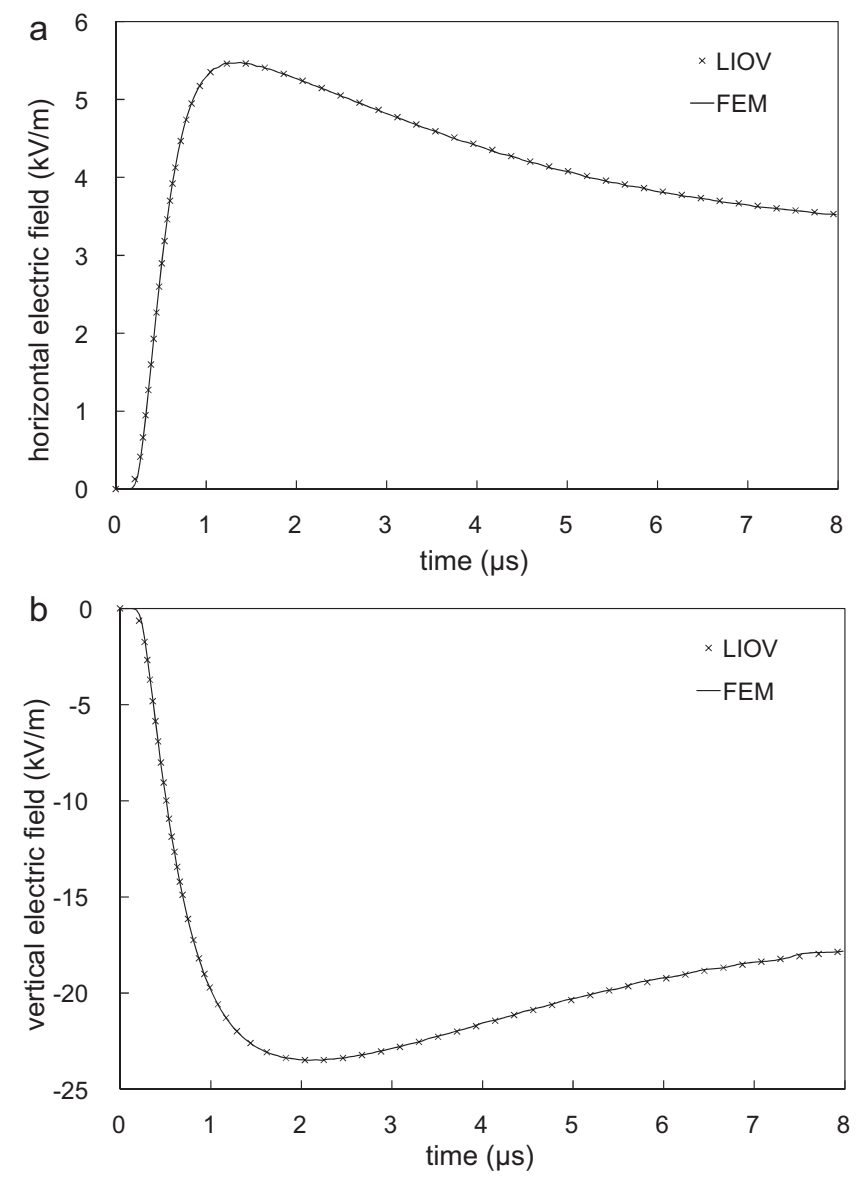

Fig. 2. Comparison between the electric field components calculated without the building by using FEM model with the corresponding results provided by the LIOV code: (a) horizontal component ( $x y$ plane) at $50 \mathrm{~m}$ from the channel and $10 \mathrm{~m}$ above the ground; (b) vertical component at $50 \mathrm{~m}$ from the channel and at ground level.

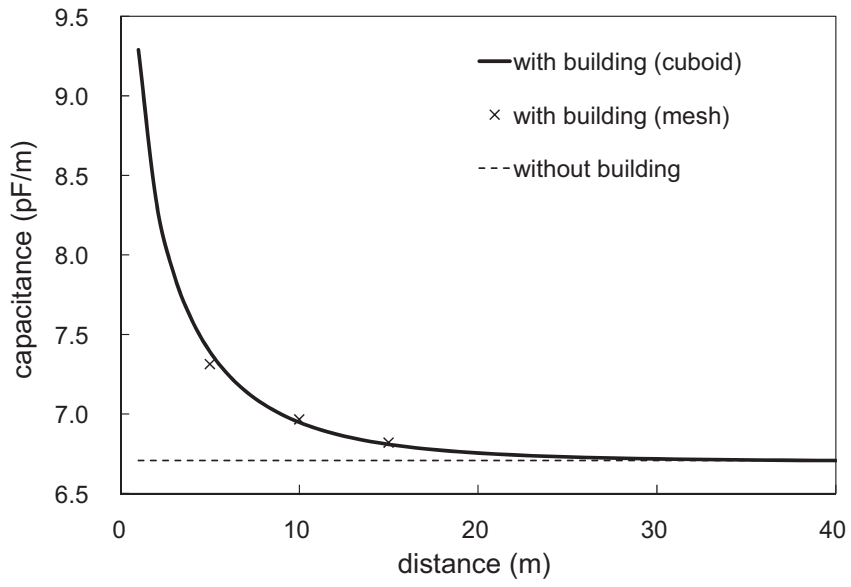

Fig. 3. Line capacitances per unit length at different distances between the line and a building with height equal to $15 \mathrm{~m}$.

the effects of the presence of a building on the LEMP waveforms. Section 4 illustrates the effects of the presence of the building on the induced voltages in a nearby overhead line and compares the results obtained for different dimensions and positions of the building with respect to the line. Section 5 is devoted to the conclusions.

\section{The finite element method model}

The considered geometry is illustrated in Fig. 1. A 1-km long 10$\mathrm{m}$ high one-conductor overhead line is placed parallel to a longer building, exceeding the line ends for $50 \mathrm{~m}$, so to study the relevant shielding effect for all the length of the line. The cross-section dimensions of the building are: $W_{\mathrm{b}}=10 \mathrm{~m}$ and $H_{\mathrm{b}}$. The analysis has been repeated for two values of $H_{\mathrm{b}}$, namely $15 \mathrm{~m}$ and $25 \mathrm{~m}$, and for three values of distance $d$ between the lightning channel and the building, namely $25 \mathrm{~m}, 30 \mathrm{~m}$ and $35 \mathrm{~m}$.

The 3D FEM model is used to calculate the LEMP in the absence of the line by means of the RF Module of the Comsol Multiphysics software [20], which implements a weak-form representation of
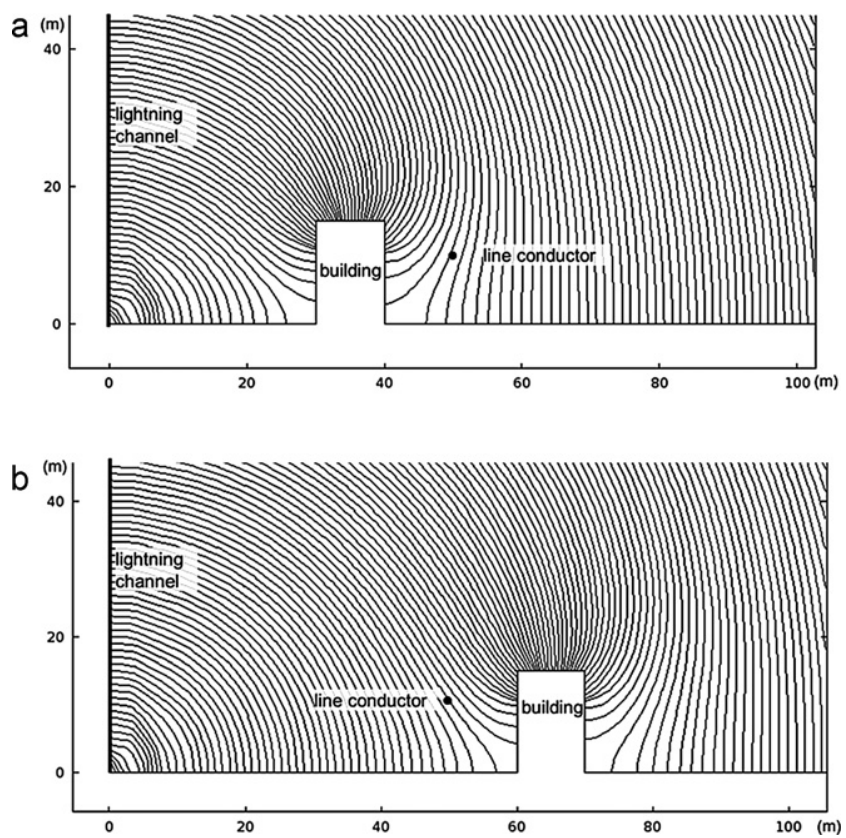

Fig. 4. Cross-sectional view of the distribution of the electric field lines at $6 \mu \mathrm{s}$ after the return stroke inception: (a) case 1 and (b) case 2. 
a)

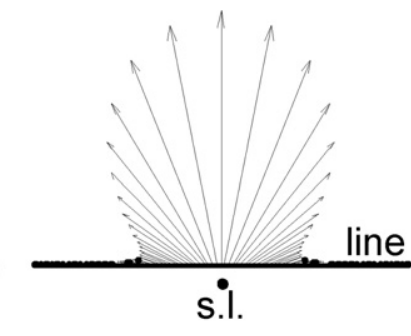

b)

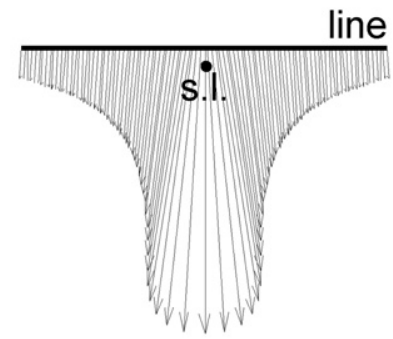

c)

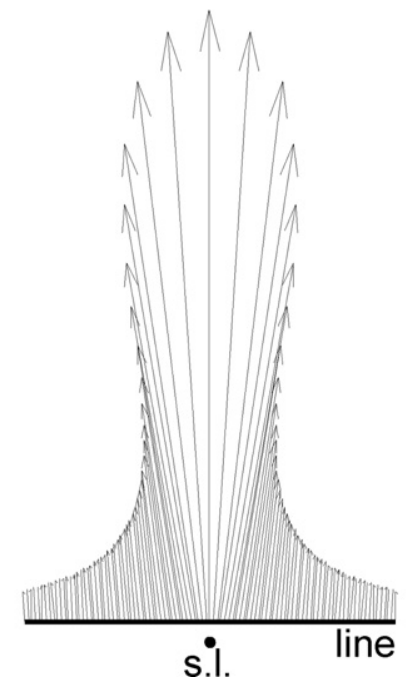

$1 \mathrm{kV} / \mathrm{m}$

Fig. 5. Top view of the horizontal components of the electric field components along the line at $6 \mu$ s after the return stroke inception: (a) without the building, (b) case 1 and (c) case 2 .

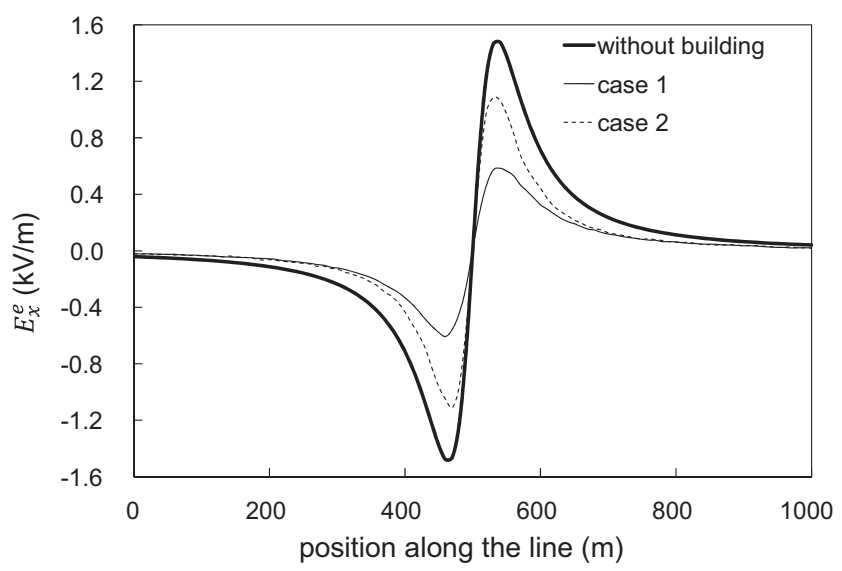

Fig. 6. Comparison of the values of $E_{x}^{e}$ calculated along the line at $6 \mu$ s after the return stroke inception with and without the building.

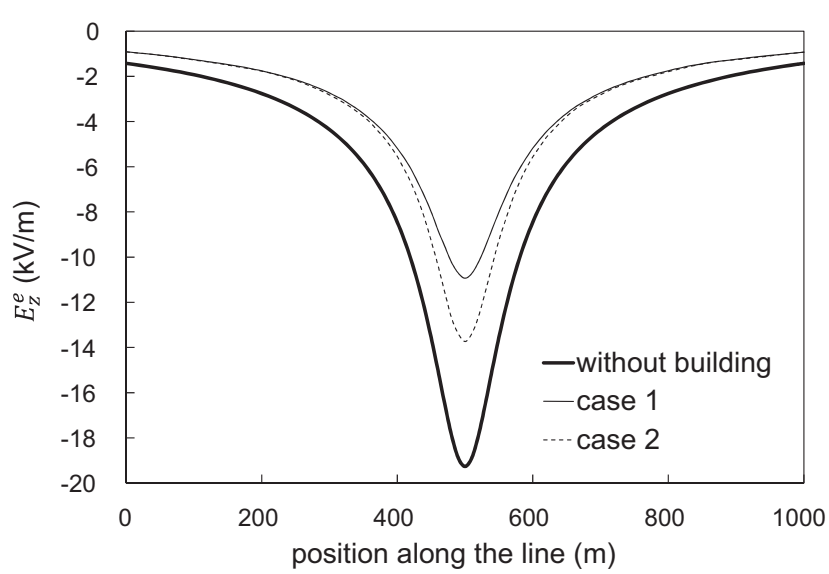

Fig. 7. Comparison of the values of $E_{z}^{e}$ calculated along the line at $6 \mu$ s after the return stroke inception with and without the building.

the time-domain wave equation of the magnetic vector potential [21].

For the source, the spatiotemporal distribution of the lightning current is defined along a $1.5 \mathrm{~km}$ high straight vertical path that represents the lightning channel. The channel is placed $50 \mathrm{~m}$ from the overhead line and equidistant to the line terminations. The instantaneous values of the lightning current are set by assuming the transmission line (TL) return stroke engineering model [22], with a return stroke wave-front velocity equal to $1.5 \times 10^{8} \mathrm{~m} / \mathrm{s}$ and a
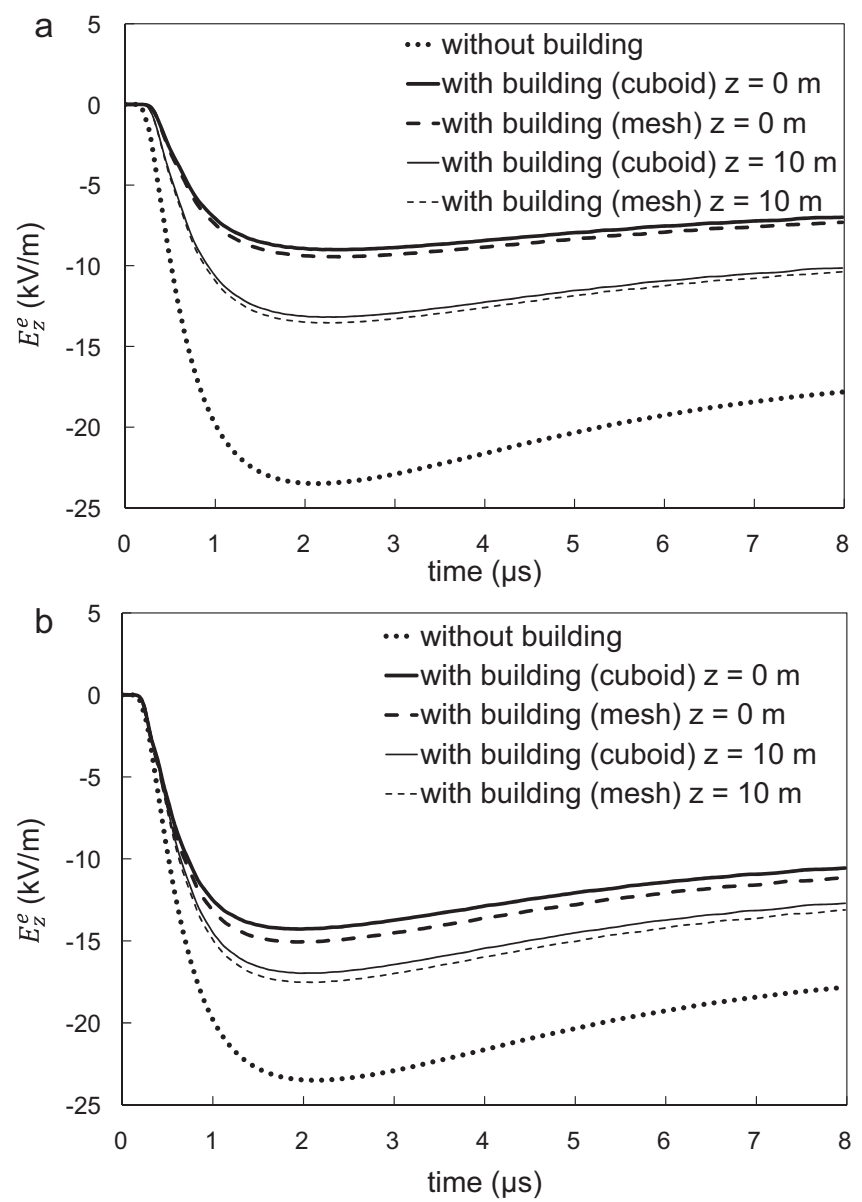

Fig. 8. Comparison between the vertical electric field in the middle point of the line with and without the building: (a) case 1 and (b) case 2 . 

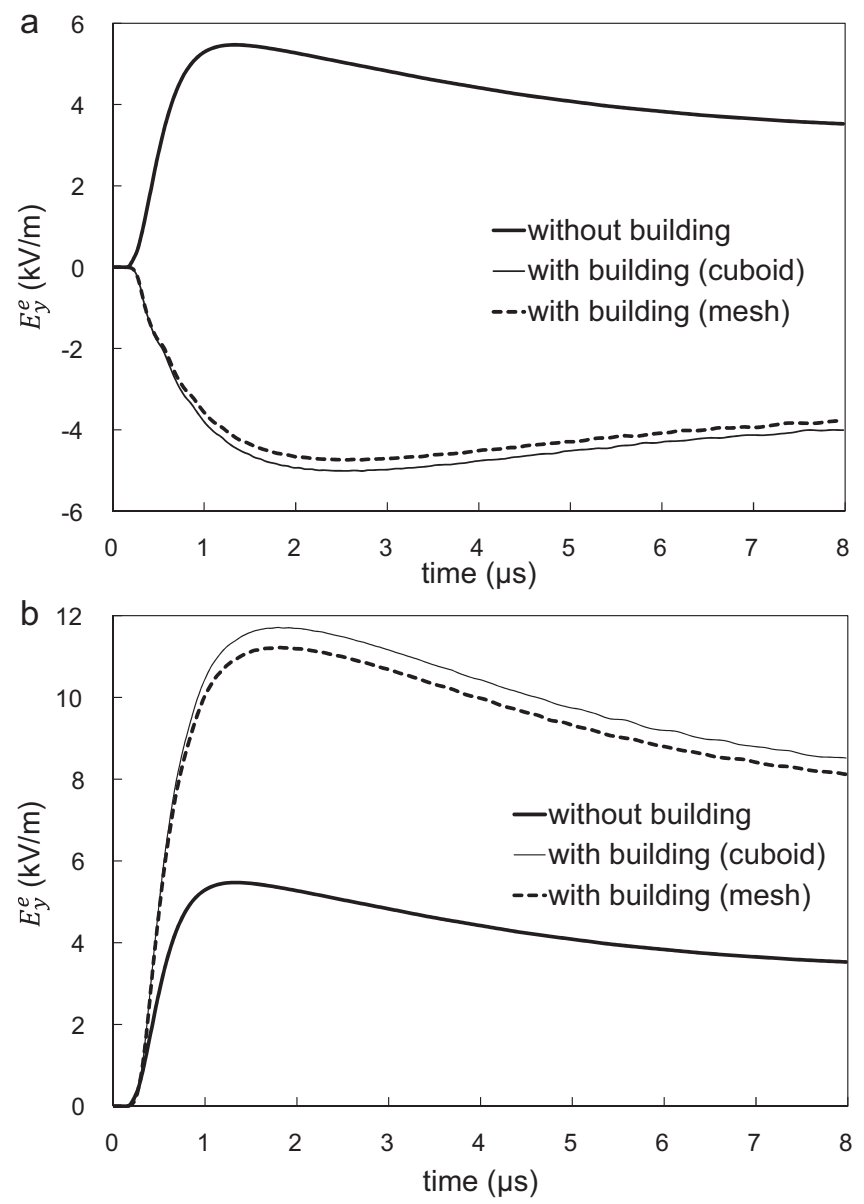

Fig. 9. Comparison between the horizontal component electric field in the middle point of the line with and without the building: (a) case 1 and (b) case 2 .

current waveform represented by the sum of two Heidler functions [23]

$I(0, t)=\frac{I_{0}}{\eta} \frac{\left(t / \tau_{1}\right)^{m}}{\left(t / \tau_{1}\right)^{m}+1} \exp \left(\frac{-t}{\tau_{2}}\right)$

As in all the other numerical example reported in this paper, the lightning current at the channel base is represented by two Heidler functions with the following parameters: $I_{01}=10.7 \mathrm{kA}, \tau_{11}=0.25 \mu \mathrm{s}, \tau_{12}=2.5 \mu \mathrm{s}, n_{1}=2, \eta_{1}=0.6394$, and $I_{02}=6.5 \mathrm{kA}, \tau_{21}=2.1 \mu \mathrm{s}, \tau_{22}=230 \mu \mathrm{s}, n_{2}=2, \eta_{2}=0.9957$.

The model includes a $3 \mathrm{D}$ domain large enough so to avoid the effects of reflections at the boundaries. Such a domain is a quarter of a $1.5 \mathrm{~km}$ radius sphere with the lightning channel as vertical edge.

Fig. 2 shows the comparison between the time waveforms of the electric fields at $50 \mathrm{~m}$ from the channel calculated by using the 3D FEM model and by the LIOV code, in the absence of both the building and the overhead line. Fig. 2a shows the comparison between the projections of the electric fields on a plane perpendicular to the channel (horizontal components) and Fig. 2b shows the comparison between the projections of the electric fields along the direction of the channel (vertical components). This comparison demonstrates that, without the presence of buildings, the two approaches provide the same results.

The two following models of the building have been implemented and compared.

(1) As a first approximation, the building is represented by a cuboid with perfectly conducting surfaces. The internal volume of the cuboid is excluded from the calculation domain.
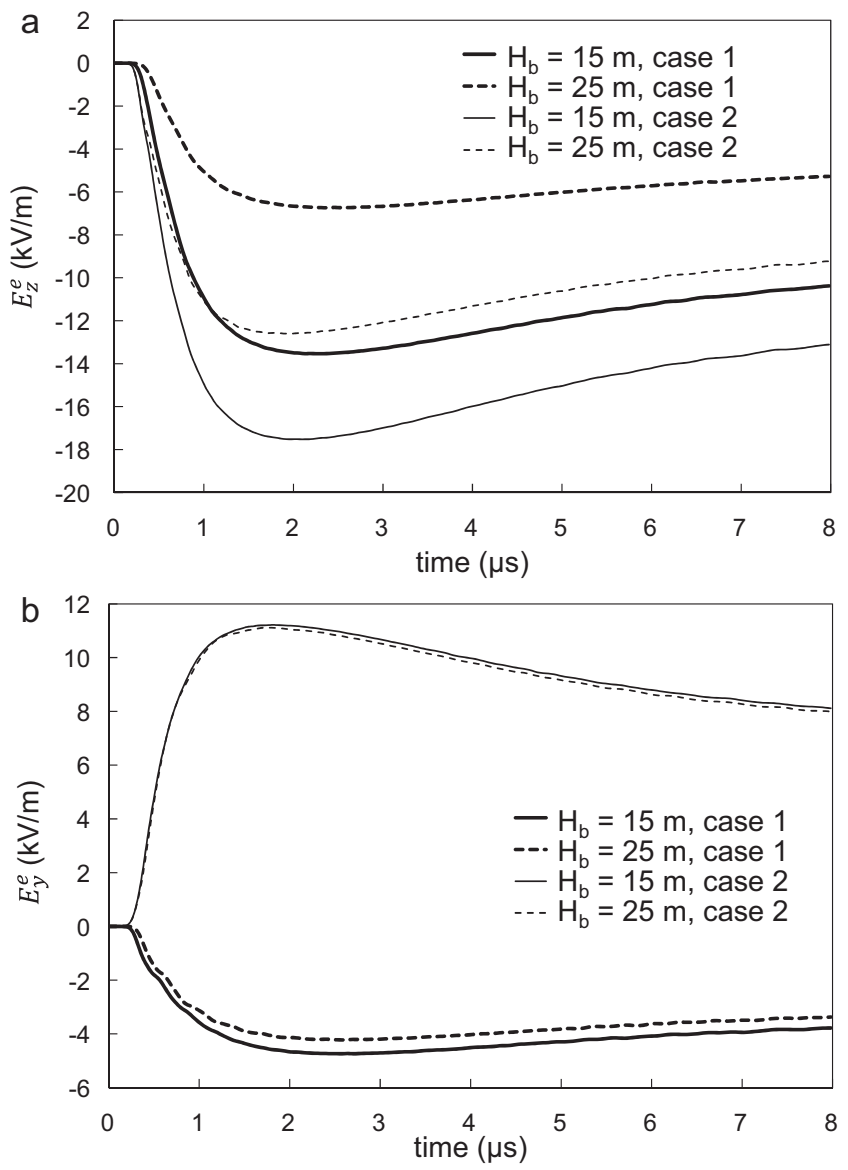

Fig. 10. Comparison between the electric field in the middle point of the line for different building heights: (a) vertical components and (b) horizontal components.

(2) An improved representation of the building consists in a mesh of cubes with edges being constituted by $5 \mathrm{~m}$ long metallic thin wires, since the shielding effect is attributed mainly to the steel rebars embedded inside reinforced concrete. In this second model, the LEMP is calculated also inside the building.

The same geometry of Fig. 1, without the lightning channel but including both the overhead line and the building, has been adopted for the calculation of the values of the line capacitance per unit length by using the Comsol AC/DC module (electrostatic solver [24]). Fig. 3 shows the line capacitance values calculated for different distances between the line and the building assuming $H_{\mathrm{b}}=15 \mathrm{~m}$. The values obtained by using the two different models of the building are very similar and for distances beyond $30 \mathrm{~m}$ they tend to the capacitance value of the line without the building. Line inductances are estimated from the corresponding capacitance values taking into account that in a lossless line the propagation speed is equal to the speed of light in vacuum. The obtained capacitance and inductance values are adopted as line parameters for the calculation of the induced voltages shown in Section 4.

\section{Attenuation of lightning electromagnetic field by the building}

We make reference to two different configurations:

Case 1 . The building is placed between the lightning channel and the line $(d=30 \mathrm{~m})$; 

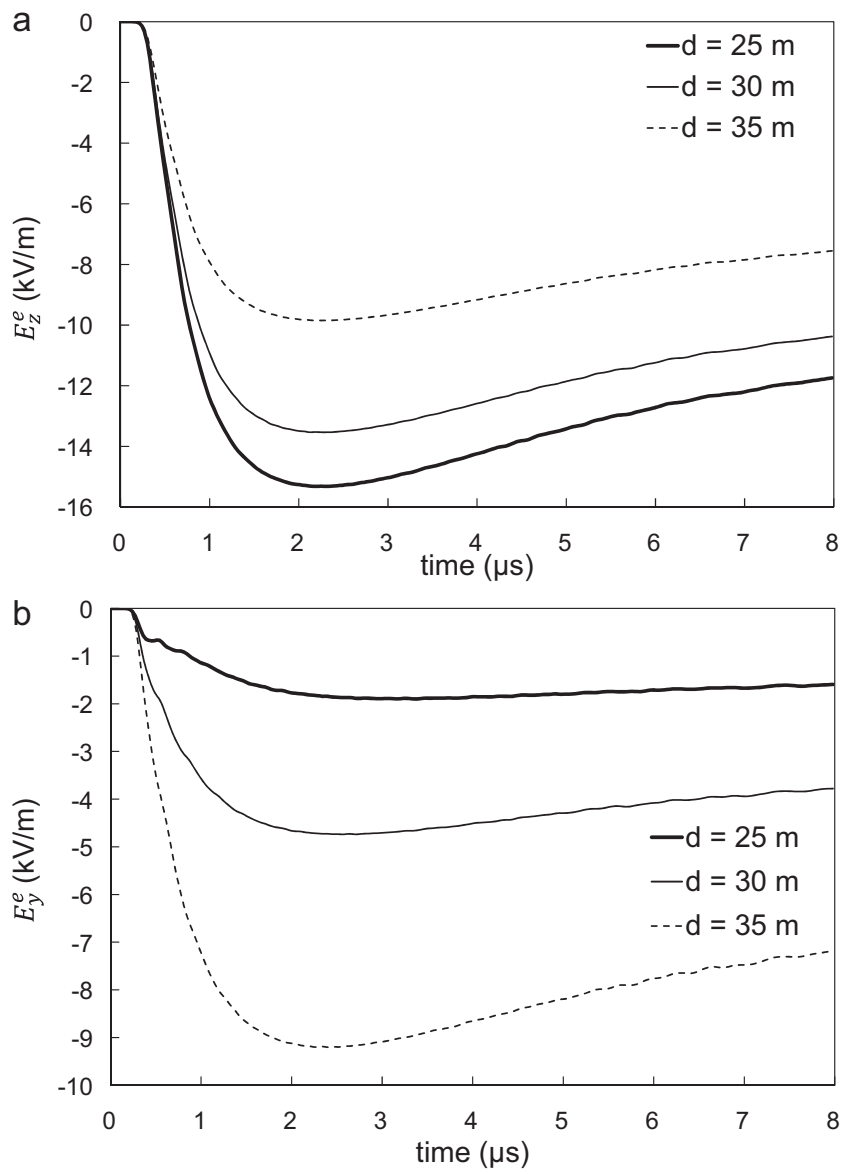

Fig. 11. Comparison between the electric field in the middle point of the line for different positions of the building: (a) vertical components and (b) horizontal components.

Case 2. The building is placed at the opposite side of the line with respect to the channel $(d=60 \mathrm{~m})$.

For both cases, Fig. 4 shows the cross-sectional view of the electric field lines calculated at $6 \mu \mathrm{s}$ after the return stroke inception, together with the position of the line conductor, the profile of the building and the position of the lightning channel. As shown in the figure, the presence of the building has two effects:

- it hides the lowest part of the channel from the line when the building is placed between the channel and the line;

- it causes a deviation of the electric field lines in the vicinity of the building.

The second effect deserves some additional comments. Fig. 5 shows the top view of the horizontal electric field calculated at several points of the overhead line for the three configurations: without building (Fig. 5a), case 1 (Fig. 5b), and case 2 (Fig. 5c). It can be observed that the presence of the building increases the intensity of this field in all the points along the line. Moreover, for case 1 the horizontal field exhibits an opposite direction with respect to the other two configurations, consistently with the cross-sectional view of the electric field lines shown in Fig. 4.

For the problem of interest, according to the Agrawal et al. model, the calculation of the induced voltages is based on the two components of the electric field (vertical and horizontal along the line direction) earlier defined in Section 1, namely $E_{z}^{e}$ and $E_{x}^{e}$. Fig. 6 shows the value of $E_{x}^{e}$ component along the line without and with the building (case 1 and case 2 ) calculated at $6 \mu \mathrm{s}$. With respect to
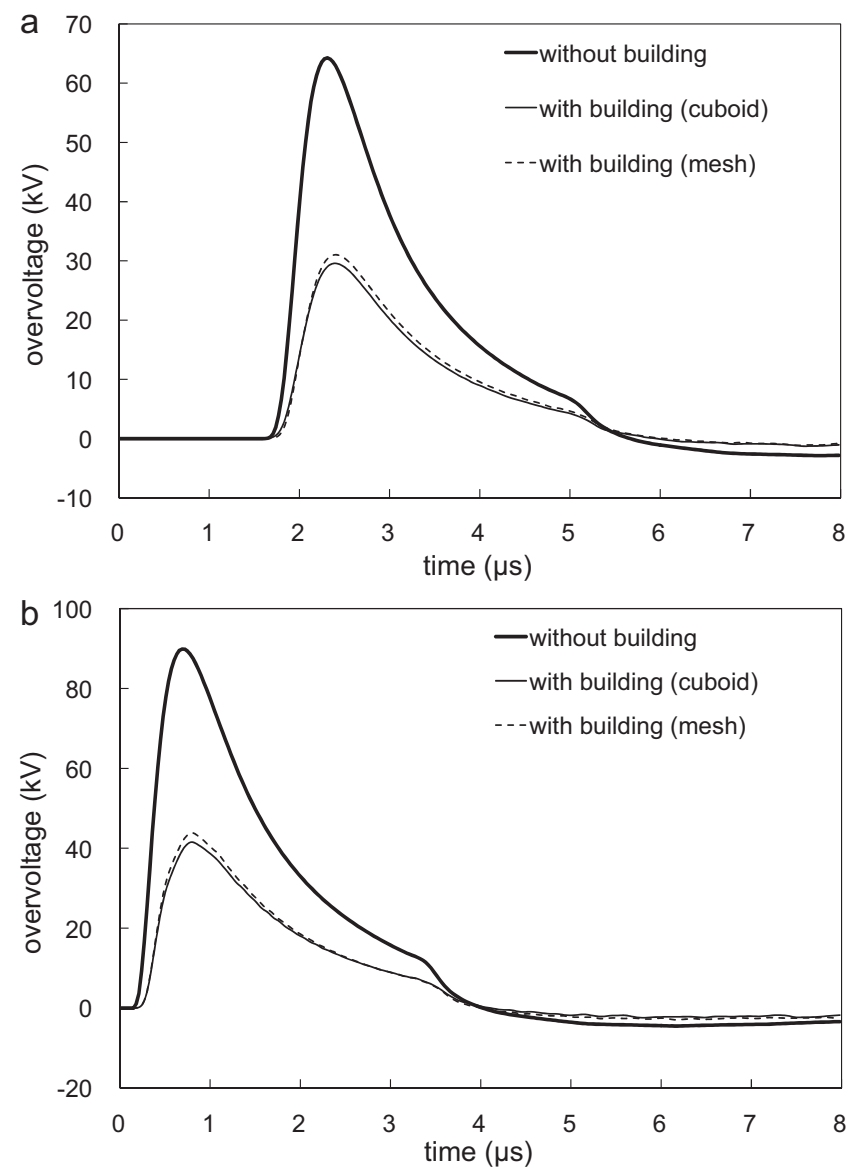

Fig. 12. Comparison between the induced overvoltages with and without building (case 1): (a) at one of the two line terminations and (b) in the middle point of the line.

the situation when the building is not present, as the building is parallel to the line, the horizontal electric field shown in Fig. 5 assume directions more perpendicular to the line and, therefore, the component of the horizontal field along the line direction $E_{x}^{e}$ decreases, as clearly shown by Fig. 6 (this can be inferred also through a careful observation of Fig. 5). Fig. 7, for completeness, compares the values of $E_{z}^{e}$ along the line calculated at $6 \mu$ s without and with the building (case 1 and case 2 ).

Fig. 8 shows the waveshapes of the vertical field at the middle point of the line ( $50 \mathrm{~m}$ far from the lightning channel) both at the height of the conductor $(z=10 \mathrm{~m})$ and at ground level $(z=0)$. If the building is not present, the vertical electric field calculated at $z=10 \mathrm{~m}$ exhibits almost the same value as at ground level. The presence of the building reduces the vertical field, which at $z=10 \mathrm{~m}$ differs significantly from the one at $z=0$.

Fig. 9 compares the corresponding waveshapes of the horizontal electric field, at the closest point of the line (where $E_{x}^{e}=0$ ) without and with the building (case 1 and case 2). Both Figs. 8 and 9 show that, for the considered configurations, the two different representations of the building, cuboid or meshed, provide similar results.

By representing the building with a wire mesh, Fig. 10 compares the vertical and horizontal electric fields at $50 \mathrm{~m}$ from the lightning channel for two different heights of the building (namely, $H_{\mathrm{b}}=15 \mathrm{~m}$ and $25 \mathrm{~m}$ ). Likewise, Fig. 11 compares the electric field waveshapes at $50 \mathrm{~m}$ from the lightning channel for three different distances of the building from the channel (namely, $d=25 \mathrm{~m}, 30 \mathrm{~m}$, and $35 \mathrm{~m}$ ), being the building always placed in between the line and the channel. The figures show that the waveshape of the horizontal electric field is slightly affected by the increased height of the 

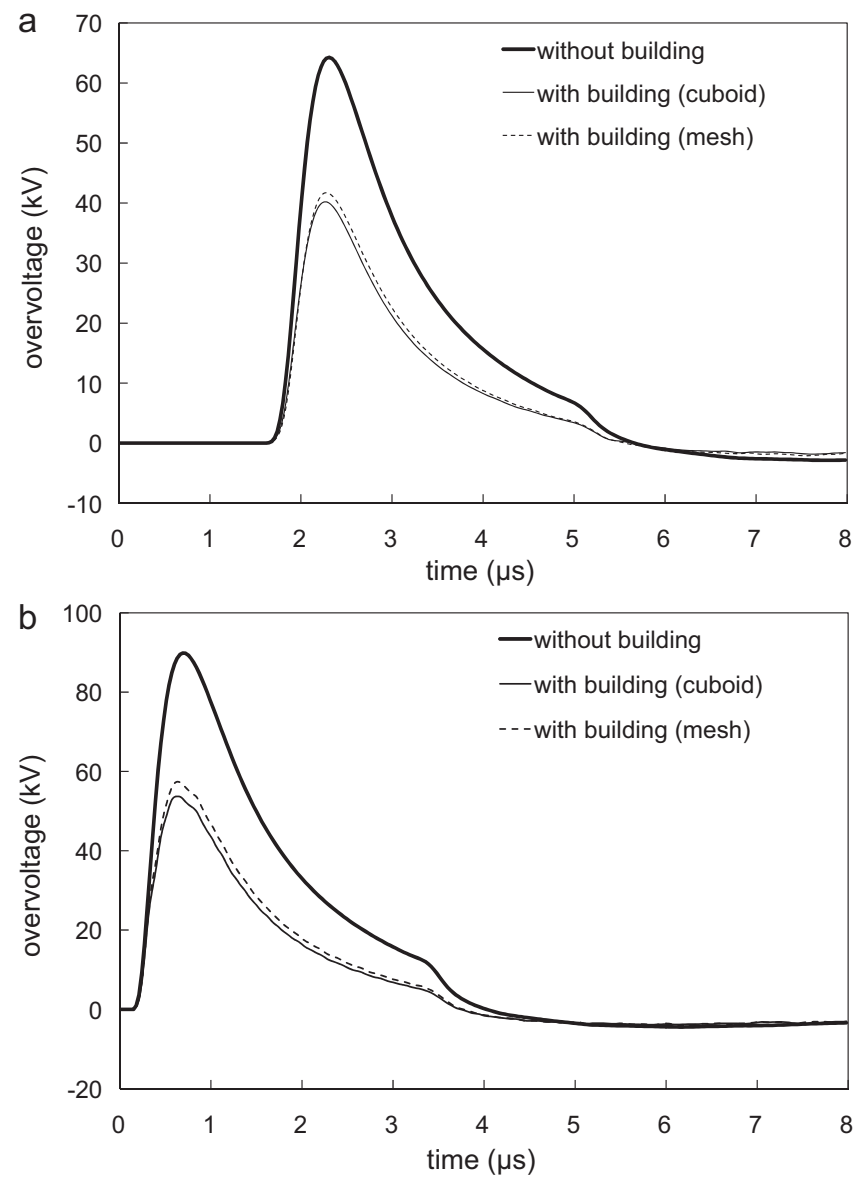

Fig. 13. Comparison between the induced overvoltages with and without building (case 2): (a) at one of the two line terminations and (b) in the middle point of the line.

building, whilst it significantly increases as the building approaches the observation point. The vertical electric field decreases either when $H_{\mathrm{b}}$ or $d$ increase.

\section{Effect of the building on the induced overvoltages}

This section compares the overvoltages induced in the overhead line with and without the building. The line is terminated at both ends with the surge impedance.

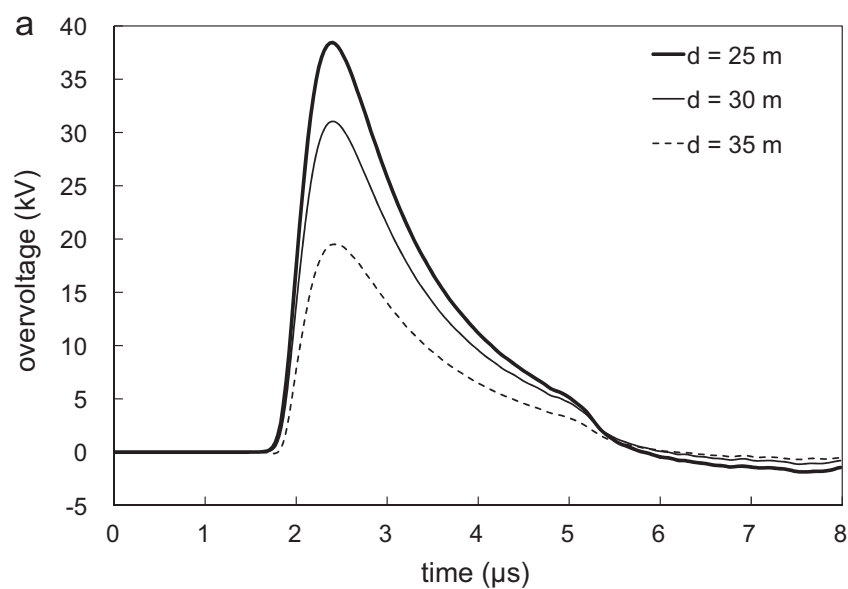

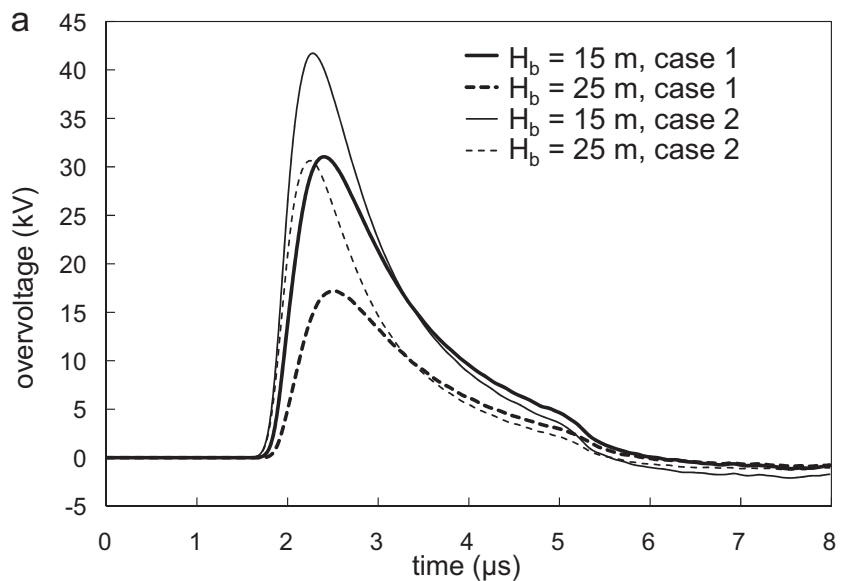

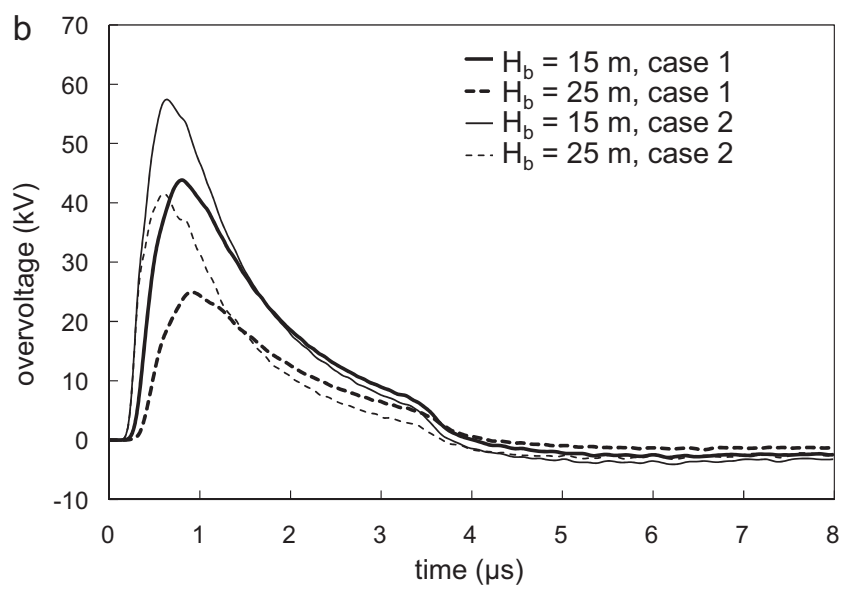

Fig. 14. Comparison between the induced overvoltages for different building heights: (a) at one of the two line terminations and (b) in the middle point of the line.

Fig. 12 compares between the case of absence of building and case 1, while Fig. 13 refers to case 2. Figs. 12a and 13a show the induced overvoltages at the middle section of the line, Figs. $12 \mathrm{~b}$ and $13 \mathrm{~b}$ at the line terminations. The obtained results show that the building reduces the lightning induced overvoltages and this effect is also present, to a minor yet significant extent, if the building is located at the opposite side of the line respect to the lightning channel, in agreement with what previously illustrated concerning the two components of the exciting electric field. For

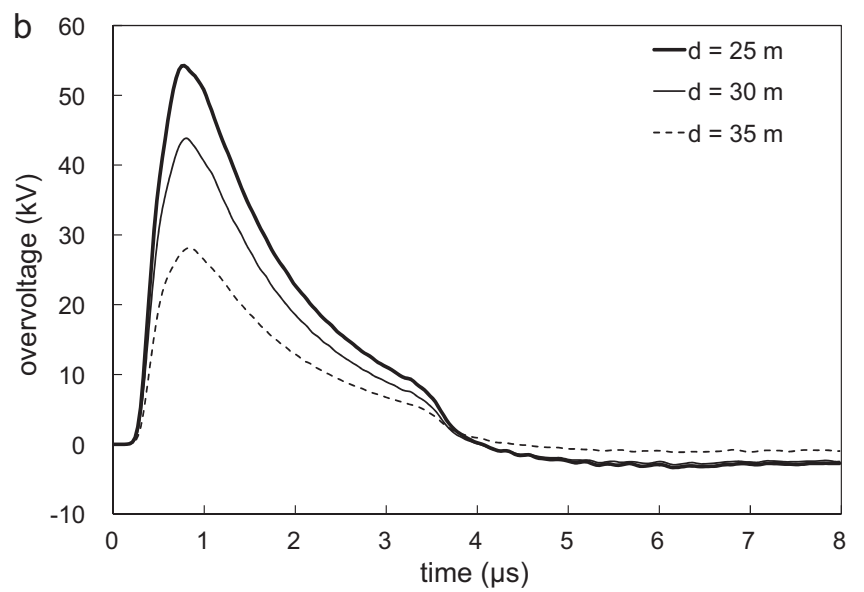

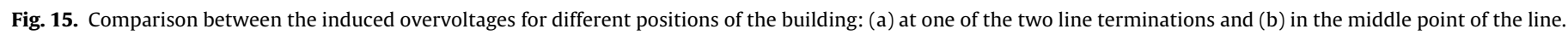



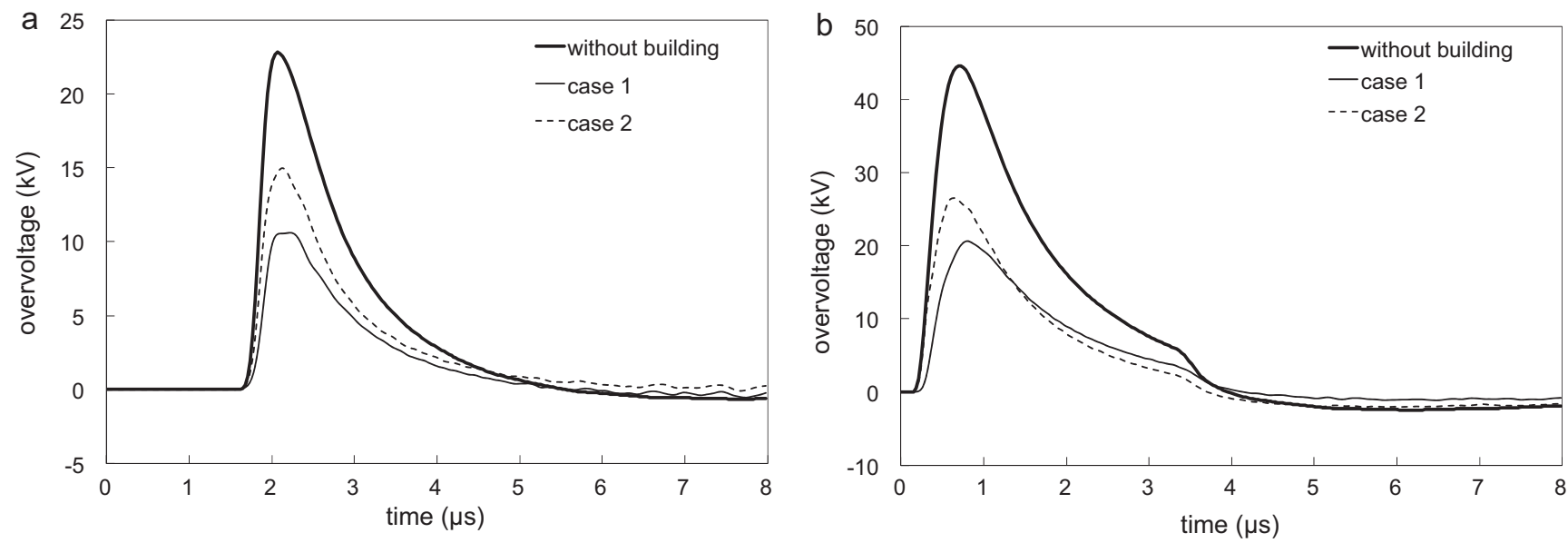

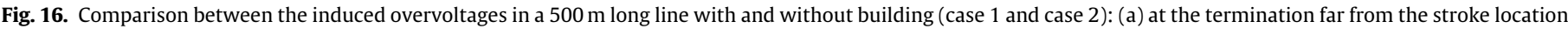
and (b) at the near termination.

the calculation of the lightning induced overvoltages, the two models adopted for the building (cuboid and meshed) provide almost the same results.

As done in the previous section, we present also the results obtained for different building heights $H_{\mathrm{b}}$ and positions $d$. For these comparisons, the adopted model of the building is the thin wire mesh. Fig. 14 compares the induced voltages calculated for $H_{\mathrm{b}}=15 \mathrm{~m}$ and $25 \mathrm{~m}$, being all the other model parameters unchanged. Fig. 15 compares the induced voltages obtained for $d=20 \mathrm{~m}, 30 \mathrm{~m}$, and $35 \mathrm{~m}$. As shown by Fig. 14, the enhanced attenuation provided by the taller building is significant also when it is located at the opposite side of the line. Figs. 14 and 15 show that the attenuation effect is present in the induced voltages calculated both in the middle point of the line and at the terminations.

In order to illustrate the effect of a stroke location closer to a line termination, Fig. 16 shows the comparison between the induced voltages calculated removing one half of the line, for the three conditions, namely without the building, with a $15 \mathrm{~m}$ high building located in between the line and the channel (case 1), and with the building located on the opposite side of the line (case 2). These results confirm that as far as the building façade is parallel to the overhead line, the electric field component along the line direction is reduced, as well as the induced voltages, with respect to the condition in which the building is not present.

\section{Conclusions}

The presence of nearby buildings may cause a reduction of the lightning induced voltage on an overhead line through two effects: the building hides the lower part of the channel and reduces the amplitude of the exciting electric field components that are responsible for the generation of lightning induced overvoltages in its vicinity. Interestingly, the second effect is also present - although to a reduced extent - if the building is situated at the opposite side of the line with respect to the lightning channel. Also, the results obtained by using the proposed procedure that involves both a 3D FEM model for the calculation of the LEMP and the solution of the field-to-line coupling equations appear to be consistent with the measurements presented in $[9,10]$ obtained using reduced scale model.

For the evaluation of the attenuation effect of the building, the results obtained by representing the building as a cuboid with perfectly conducting surfaces differ slightly from those obtained by a more realistic model that represent the meshed structure of the steel rebars of the reinforced concrete.

\section{Acknowledgments}

This paper is a revised and extended version of contribution [25] kindly presented by Professor Marcos Rubinstein at the 2011 AsiaPacific International Conference on Lightning (APL). We would like to thank the presenter and participants for their helpful comments and suggestions.

\section{References}

[1] A.A. Smith, Attenuation of electric and magnetic fields by buildings, IEEE Transactions on Electromagnetic Compatibility 20 (3) (1978) 411-418.

[2] A. Orlandi, C. Mazzetti, Z. Flisowski, M. Yarmarkin, System approach for the analysis of the electromagnetic environment inside a building during lightning strike, IEEE Transactions on Electromagnetic Compatibility 40 (4) (1998) 521-535.

[3] G. Maslowski, M. Gamracki, Protection of structures against LEMP, in: Proc. of 2003 IEEE Bologna Power Tech Conference Proceedings, Italy, 23-26 June, 2003

[4] I.A. Metwally, F.H. Heidler, Reduction of lightning-induced magnetic fields and voltages inside struck double-layer grid-like shields, IEEE Transactions on Elec tromagnetic Compatibility 50 (4) (2008) 905-912.

[5] J. Chen, B. Zhou, F. Zhao, S. Qiu, Finite-difference time-domain analysis of the electromagnetic environment in a reinforced concrete structure when struck by lightning, IEEE Transactions on Electromagnetic Compatibility 52 (4) (2010) 914-920.

[6] S. Bonyadi-Ram, R. Moini, S.H.H. Sadeghi, A. Mahanfar, The effects of tall buildings on the measurement of electromagnetic fields due to lightning return strokes, in: Proc. 2001 IEEE EMC International Symposium, Montreal, Canada 2001

[7] Y. Baba, V.A. Rakov, Electromagnetic fields at the top of a tall building associated with nearby lightning return strokes, IEEE Transactions on Electromagnetic Compatibility 49 (3) (2007) 632-643.

[8] A. Mosaddeghi, D. Pavanello, F. Rachidi, M. Rubinstein, P. Zweiacker, Effect of nearby buildings on electromagnetic fields from lightning, Journal of Lightning Research 1 (2009) 52-60.

[9] A. Piantini, J.M. Janiszewski, C.P. Braz, Utilization of reduced models for the analysis of lightning induced overvoltages on overhead lines, in: Proc. 2010 International Conference on High Voltage Engineering and Application, ICHVE October 11-14, 2010, pp. 160-163.

[10] A. Piantini, J.M. Janiszewski, A. Borghetti, C.A. Nucci, M. Paolone, A scale mode for the study of the LEMP response of complex power distribution networks, IEEE Transactions on Power Delivery 22 (1) (2007) 710-720.

[11] C.A. Nucci, F. Rachidi, M. Ianoz, C. Mazzetti, Lightning-induced voltages on overhead lines, IEEE Transactions on Electromagnetic Compatibility 35 (1) (1993) 75-86.

[12] F. Rachidi, C.A. Nucci, M. Ianoz, C. Mazzetti, Influence of a lossy ground on lightning-induced voltages on overhead lines, IEEE Transactions on Electromagnetic Compatibility 38 (3) (1996) 250-264

[13] F. Napolitano, A. Borghetti, C.A. Nucci, M. Paolone, F. Rachidi, J. Mahseredjian, An advanced interface between the LIOV code and the EMTP-RV, in: Proc. 29th Int Conf. on Lightning Protection ICLP 2008, Uppsala, Sweden, June 23-26, 2008.

[14] A.K. Agrawal, H.J. Price, S.H. Gurbaxani, Transient response of multiconductor transmission lines excited by a nonuniform electromagnetic field, IEEE Transactions on Electromagnetic Compatibility 22 (2)(1980) 119-129. 
[15] M. Paolone, C.A. Nucci, F. Rachidi, A new finite difference time domain scheme for the evaluation of lightning induced overvoltages on multiconductor overhead lines, in: Proc. of 5th International Conference on Power System Transients, Rio de Janeiro, June, 2001.

[16] M.J. Master, M.A. Uman, Transients electric and magnetic fields associated with establishing a finite electrostatic dipole, American Journal of Physics 51 (2) (1983) 118-126.

[17] V. Cooray, Horizontal fields generated by return strokes, Radio Science 27 (4) (1992) 529-537.

[18] M. Rubinstein, An approximate formula for the calculation of the horizontal electric field from lightning at close, intermediate, and long range, IEEE Transactions on Electromagnetic Compatibility 38 (3) (1996) 531-535.

[19] V. Cooray, Some considerations on the "Cooray-Rubinstein" formulation used in deriving the horizontal electric field oh lightning return strokes over finitely conducting ground, IEEE Transactions on Electromagnetic Compatibility 44 (4) (2002) 560-566.

[20] RF Module User's Guide, October 2010, COMSOL AB.

[21] J.-M. Jin, D.J. Riley, Finite Element Analysis of Antenna and Arrays, John Wiley \& Sons Inc., Hoboken, 2009.

[22] M.A. Uman, D.K. McLain, Magnetic field of lightning return stroke, Journal of Geophysical Research 74 (28) (1969) 6899-6910.

[23] F. Heidler, Analytische blitzstromfunktion zur LEMP-berechnung, in: Proc. 18th Int. Conf. Lightning Protection, Munich, Germany, paper 1.9, September, 1985, pp. 63-66.

[24] COMSOL AC/DC Module User's Guide, April 2010, COMSOL AB.

[25] A. Borghetti, F. Napolitano, C.A. Nucci, M. Paolone, Calculation of lightninginduced voltages on an overhead line taking into account the presence of nearby buildings, in: Proc. of 7th Asia-Pacific International Conference on Lightning (APL), Chengdu, China, November 1-4, 2011, pp. 833-839. 